\title{
BLOOD ZINC LEVEL IN CHILDREN WITH COMBINED GASTROESOPHAGEAL REFLUX DISEASE AND CHRONIC GASTRODUODENAL PATHOLOGY
}

\author{
Olga Belousova \\ Department of Pediatric Gastroenterology and Nutrtiology \\ Kharkiv Medical Academy of Postgraduate Education \\ 58 Amosova str., Kharkiv, Ukraine, 61176 \\ olga.yu.belousova@gmail.com \\ Nataliia Kirianchuk ${ }^{1}$ \\ talitaK@ukr.net \\ Tetiana Zimnytska \\ zim01tv@gmail.com \\ ${ }^{1}$ Department of Pediatrics No. 2 \\ V. N. Karazin Kharkiv National University \\ 4 Svobody sq., Kharkiv, Ukraine, 61022
}

\begin{abstract}
Pathology of the upper digestive tract is the most common among gastroenterological diseases in children of different ages and is $48-50 \%$. Recently, there has been an increase in combined lesions of the esophagus and organs of the gastroduodenal zone. Currently, microelements are considered to play a role in the etiopathogenesis of the diseases of the gastrointestinal tract.

The aim of the work was to study zinc level in the blood of children with combined gastroesophageal reflux disease (GERD) and chronic gastroduodenal pathology.

Materials and methods. 110 children with combined GERD and lesions of the gastroduodenal zone at the age of 10-18 years were under observation. In order to verify the diagnosis, esophagogastroduodenoscopy was performed. The level of zinc in the blood of children was studied using photometric method.

Results. $52.5 \%$ of children with concomitant GERD and chronic gastroduodenal pathologies had a reduced zinc level in the blood. According to the results of the study, the risk factors of zinc deficiency in children with combined pathology of the upper digestive tract include male sex, age older than 14 years, the duration of the disease longer than 3 years. The level of zinc in the blood of children was significantly reduced in destructive lesions of the esophagus, as well as with more pronounced inflammation of the gastric mucosa, in duodenitis and erosions in the duodenal bulb.

Conclusions. Thus, the results of the study showed the importance of studying the level of zinc in the blood of patients with combined GERD and chronic gastroduodenal pathology to achieve positive changes by its correction. Zinc deficiency more often develops in boys over 14 year old, who has inflammatory changes of digestive tract.
\end{abstract}

Keywords: gastroesophageal reflux disease, chronic gastroduodenal pathology, children, zinc.

DOI: $10.21303 / 2504-5679.2019 .001088$

\section{Introduction}

Pathology of the upper digestive tract is the most common among children of different ages suffering gastroenterological diseases and makes 48-50\% [1]. Recently, there has been an increase in combined lesions of the esophagus and organs of the gastroduodenal zone [2]. Much attention is currently paid to the role of microelements in the etiopathogenesis of the diseases of the gastrointestinal tract, $[3,4]$. According to the authors, essential microelements have a significant influence on gastric secretion, production of protective factors of the gastric mucosa and duodenum, reverse diffusion of hydrogen ions, physiological activity of hormones and vitamins, tissue respiration $[5,6]$. Much attention is paid to the role of zinc, which is deficient in about $17 \%$ of the world population [7]. In the literature, the antiulcerogenic properties of zinc are widely covered, which are due to both its inhibitory effect on gastric secretion and the ability to block the release of the secretory and inflammatory agent histamine from basophilic cells, which is involved in damage of the trophic 
mucosa of the stomach and duodenum in peptic ulcer disease [8, 9]. Zinc restores biosynthesis of prostaglandin E2, stimulates the formation of mucus in the stomach $\mathrm{X}[10,11]$.

The results of the studies revealed an increased amount of zinc in the gastric mucosa of patients with chronic gastroduodenal pathology against the background of a decrease of this bioelement in the blood [12]. The researchers explained the multidirectional nature of changes in the level of zinc in the blood and mucous membranes of the stomach at the stage of exacerbation of gastroduodenal ulcers by the ability of the metal to redistribute from the blood into the tissue. This is due to the body's increased need for zinc to heal the damaged mucous membrane of the stomach and duodenum [13].

In addition to the effect on the local immunity of the gastric mucosa, according to the authors, zinc has an antimicrobial effect against $H$. pylori, which may be due to its ability to stabilize the conformation of the antimicrobial peptide histatin-5, which is present in saliva and is able to lyse microorganisms only in the presence of zinc $[14,15]$.

Despite the extensive study of the protective role of zinc in chronic gastroduodenal pathology, the influence of zinc on the development of gastroesophageal disease and its progression remains unproved.

The studies conducted in adults have shown that patients with a high concentration of zinc in esophageal biopsies had a reduced risk of esophageal squamous cell carcinoma [16].

There are also reports of a decreased zinc in serum of patients with GERD who took proton pump inhibitors for a long period of time [17]. In this regard, the study of zinc level in the blood of children suffering from combined diseases of the upper digestive tract for more than 3-5 years is of a particular interest. The problem of zinc deficiency in this category of patients does not seem to be less important.

Aim of the the research - to study zinc level in the blood of children with combined gastroesophageal reflux disease (GERD) and chronic gastroduodenal pathology.

\section{Materials and methods}

110 children with combined GERD and chronic gastroduodenal pathology at the age of 10-18 years, admitted to a municipal non-commercial enterprise - City Clinical Hospital No. 19 of Kharkiv City Council (Kharkiv, Ukraine), were under observation from 2013 to 2018. In order to verify the diagnosis of gastroesophageal reflux disease, as well as concomitant gastroduodenal pathology, all children were performed standard esophagogastroduodenoscopy. 110 children with combined GERD and lesions of the gastroduodenal zone at the age of 1018 years, admitted to City Clinical Hospital No. 19 of Kharkiv City Council (Kharkiv, Ukraine), were under observation. In order to verify the diagnosis of gastroesophageal reflux disease, as well as concomitant gastroduodenal pathology, all children were performed standard esophagogastroduodenoscopy.

All the children were tested for serum zinc level using photometric method in the laboratory of the Ecomed Medical Center (license AB, No. 539111). Reference values of zinc level in blood ranged from $12.8 \mathrm{mmol} / 1$ to $18 \mathrm{mmol} / 1$ [18].

The study was carried out in accordance with the principles of the Helsinki Declaration. The study protocol was approved by the Local Ethics Committee (LEC) of Kharkov Medical Academy of Postgraduate Education (protocol No. 3, 2019) Informed consent of the children's parents (or guardians) was obtained for the research.

Statistical data processing was performed with the help of SPSS 19.0 application package. Quantitative and qualitative variables were used in the statistical analysis. Qualitative data were presented as percentages; quantitative data were presented as mean and standard error $(\mathrm{M} \pm \mathrm{m})$. The Student's t-test was used to compare quantitative indicators in independent samples. The critical significance level for testing statistical hypotheses in the study was assumed to be 0.05 .

\section{Result}

The results of the study showed that $52.5 \%$ of children with combined GERD and chronic gastroduodenal pathology had a decreased level of zinc in the blood. 
The level of zinc in the blood of children depending on age was studied (Table 1). Combined GERD and chronic gastroduodenal pathology were diagnosed mainly in children older than 14 years $(73.6 \%)$. In this age group, a lower mean blood zinc level $(\mathrm{p}<0.01)$ was observed as compared to the younger age group.

Table 1

Zinc level in blood of children with combined GERD and chronic gastroduodenal pathology depending on age $(\mathrm{mmol} / \mathrm{l})$

\begin{tabular}{cc}
\hline Age & Zinc level \\
\hline $10-14$ years $(\mathrm{n}=29)$ & $12.94 \pm 0.51$ \\
$15-18$ years $(\mathrm{n}=81)$ & $11.43 \pm 0.29^{*}$ \\
Norm & $12.8-18.0$
\end{tabular}

Note: statistically significant difference $(p<0.01)$ in mean zinc level in the blood of children of different age groups

The level of zinc in the blood of children depending on sex was also studied. Children with combined pathology of the esophagus and organs of the gastroduodenal zone were mainly boys $(80.9 \%)$.

As is seen from Table 2 , the average zinc level in the blood of boys was significantly $(\mathrm{p}<0.01)$ lower as compared to that in girls.

Table 2

Zinc level in blood of children with combined GERD and chronic gastroduodenal pathology depending on $\operatorname{sex}(\mathrm{mmol} / \mathrm{l})$

\begin{tabular}{cc}
\hline Sex & M $\pm \mathbf{m}$ \\
\hline Boys $(\mathrm{n}=89)$ & $11.460 .27 \pm *$ \\
Girls $(\mathrm{n}=21)$ & $13.370 .63 \pm$ \\
Norm & $12.8-18.0$
\end{tabular}

Note: statistically significant difference $(p<0.01)$ in mean level of zinc in the blood of boys and girls

Zinc levels in the blood were also influenced by the duration of the disease - it was more than 3 years in more than half of the patients (59.5\%). Among children suffering from combined pathology of the upper digestive tract for more than 3 years, there was a significant decrease in the average level of zinc $(\mathrm{p}<0.5)$ as compared with the children who were ill for less than three years (Table 3).

Table 3

Zinc level in the blood of children with combined GERD and chronic gastroduodenal pathology depending on the duration of the disease ( $\mathrm{mmol} / \mathrm{l})$

\begin{tabular}{cc}
\hline Disease duration & $\mathbf{M} \pm \mathbf{m}$ \\
\hline More than 3 years $(\mathrm{n}=61)$ & $12.430 .43 \pm$ \\
Up to 3 years $(\mathrm{n}=48)$ & $11.360 .30 \pm^{*}$ \\
Norm & $12.8-18.0$
\end{tabular}

Note: statistically significant difference $(p<0.05)$ in mean level of zinc in the blood of children with different duration of the disease

This fact can be explained by the fact that, probably, with a long-term chronic inflammatory process of the mucous membrane of the upper digestive tract, the depletion of zinc 
reserves in the body occurs. It is also necessary to take into account that in combined GERD and chronic gastroduodenal pathology, older children, as a rule, receive proton pump inhibitors for a long time, which, according to the literature, contributes to a decreased level of zinc in the blood [16].

We also studied the level of zinc in the blood in pathological changes in the mucosa of the upper digestive tract of different nature and prevalence. In assessing the condition of the esophageal mucosa, we were guided by the endoscopic classification of esophagitis and gastroesophageal reflux (G. Tytgat, V. F. Privorotsky) [19]. In most children (69 \%) GERD was accompanied by changes in the esophageal mucosa.

The results of the study showed that in the group of children with destructive lesions of the esophageal mucosa (GERD with esophagitis of I-II degree), blood zinc level is significantly lower $(p<0.001)$ as compared with the children having catarrhal changes in mucosa (GERD with esophagitis of I degree) (Table 4).

\section{Table 4}

Zinc level in blood of children with combined GERD and chronic gastroduodenal pathology depending on the condition of the esophageal mucosa $(\mathrm{mmol} / \mathrm{l})$

\begin{tabular}{cc}
\hline Condition of esophageal mucosa & M $\pm \mathbf{m}$ \\
\hline GERD without esophagitis $\mathrm{n}=34$ & $12.9 \pm 0.34$ \\
GERD with esophagitis of I degree $\mathrm{n}=43$ & $12.89 \pm 0.30$ \\
GERD with esophagitis II-III degree $\mathrm{n}=33$ & $10.58 \pm 0.52^{*}$ \\
Norm & $12.8-18.0$
\end{tabular}

Note: statistically significant difference $(p<0.001)$ in mean level of zinc in the blood of children with esophagitis of II-III degree compared with children with esophagitis of I degree

The results of the endoscopic study showed that gastroesophageal reflux disease developed in the vast number of children studied $(94.5 \%)$ against the background of chronic gastritis. Endoscopically, $35.4 \%$ of patients showed moderate erythematous gastropathy and $59.1 \%$ - pronounced erythematous gastropathy. The results of the study showed that the zinc level is significantly lower $(\mathrm{p}<0.01)$ in children with a more pronounced inflammatory process of the gastric mucosa (Table 5).

Table 5

Zinc level in the blood of children with combined GERD and chronic gastroduodenal pathology depending on the condition of the gastric mucosa $(\mathrm{mmol} / \mathrm{l})$

\begin{tabular}{cc}
\hline The condition of the gastric mucosa & M $\pm \mathbf{m}$ \\
\hline Moderate erythematous gastropathy $\mathrm{n}=39$ & $12.98 \pm 0.44$ \\
Pronounced erythematous gastropathy $\mathrm{n}=65$ & $11.34 \pm 0.31^{*}$ \\
Norm & $12.8-18.0$
\end{tabular}

Note: statistically significant difference $(p<0.01)$ in mean level of zinc in the blood of children with moderate-to-severe erythematous gastropathy and in children with severe erythematous gastropathy.

Endoscopic examination of the duodenum did not reveal any pathology in $46 \%$ of children. The mean level of zinc in the blood of these patients corresponded to the reference values (Table 6). 33 children (30\%), having the pathological process not only in the gastric but also in duodenal mucosa (endoscopically - erythematous duodenopathy), had a significant decrease $(\mathrm{p}<0.05)$ of zinc level in the blood. 31 children $(28.2 \%)$ who had destructive lesions of the duodenal mucosa (erosion of the duodenal cap) were also zinc deficient. 
Table 6

The level of zinc in the blood of children with combined GERD and chronic gastroduodenal pathology depending on the condition of the mucous membrane of the duodenum ( $\mathrm{mmol} / \mathrm{l})$

\begin{tabular}{|c|c|}
\hline Condition of the duodenal mucous membrane & $\mathbf{M} \pm \mathbf{m}$ \\
\hline Normal duodenal mucosa $n=46$ & $12.97 \pm 0.45$ \\
\hline Erythematous duodenopathy $n=33$ & $11.59 \pm 0.35^{*}$ \\
\hline Erosion of the duodenal bulbus $n=31$ & $10.3 \pm 0.32 * *$ \\
\hline Norm & $12.8-18.0$ \\
\hline
\end{tabular}

\section{Discussion}

According to the results of the study, more than half of children with combined GERD and chronic gastroduodenal pathology have a reduced level of zinc in the blood. The risk factors for the development of zinc deficiency against the background of combined pathology of the upper digestive tract proved to be male sex, age older than 14 years, as well as the duration of the disease more than 3 years.

The level of zinc in the blood decreases depending on the nature and extent of damage to the mucous membrane of the digestive tract. This is evidenced by the results of the study of zinc level in the blood of children with varying degrees of severity of esophageal mucosa. A significant decrease in zinc level in the blood was observed in children having erosive esophagitis.

The presence of concomitant pathology of the gastroduodenal zone also contributed to the development of zinc deficiency. Thus, with more pronounced inflammation of the gastric mucosa, the zinc level was significantly lower. Zinc deficiency was also found in children who had the duodenum involved into the pathological process (a destructive lesion of the duodenal bulb mucosa).

The results of the study are consistent with the literature on the increased consumption of zinc in the inflammatory process in the stomach and duodenum, accompanied by the redistribution of metal from the blood into the tissues of the digestive tract, which finally leads to its deficiency [20].

The limitations of the research. The results of the study were obtained in the study of children aged 10 to 18 years. The study did not include children with comorbidities of the other organs and systems.

The further research plan includes the study of zinc content in the blood of young children with combined diseases of the upper digestive tract, as well as the study of zinc deficiency developing in children with comorbid conditions of the other organs and systems.

\section{Conclusions}

1. Children with combined GERD and chronic gastroduodenal pathology develop zinc deficiency in $52 \%$ of cases. The risk group includes young men aged 15-18 years.

2. Zinc deficiency is more likely to develop in children with disease duration of more than 3 years.

3. Zinc content in the blood correlates with the severity of inflammatory changes in the esophagus, stomach and duodenum.

4. Thus, the results of the study showed the importance of studying the level of zinc in the blood of patients with combined GERD and chronic gastroduodenal pathology to achieve positive changes by its correction.

\section{Conflicts of interest}

No conflict of interest. 


\section{References}

[1] Pavlenko, N. V., Shutova, O. V., Hanzii, O. B., Solodovnichenko, I. G., Savytska, K. V., Slobodianiuk, O. L. (2018). Optimization of eradication treatment for chronic gastroduodenitis associated with Helicobacter pylori in children using spore recombinant probiotic based on Bacillus subtilis. Child`s Health, 13, s16-s22. doi: https://doi.org/10.22141/2224-0551.13.0.2018.131172

[2] Pavlenko, N. V., Solodovnichenko, I. G., Voloshin, K. V., Ganziy, E. V. (2013). Combined pathology of the esophagus and gastroduodenal zone in children: changing priorities. Perinatologiya i Pediatriya, 4, 85-87.

[3] Plockireva, A. A. (2011). Nutritive approaches to the correction and prophylaxis of microelemental status disorders in children. Current Pediatrics, 10 (2), 141-145.

[4] Agarwal, A., Khanna, P., Baidya, D. K., Arora, M. K. (2011). Trace Elements in Critical Illness. Journal of Endocrinology and Metabolism, 1 (2), 57-63. doi: https://doi.org/10.4021/jem24e

[5] Tarasova, L. V. (2012). The role of selenium, zinc, manganese in the pathogenesis of chronic gastritis and ulcerous disease of duodenum. Medical Almanac, 2, 234-239.

[6] Prasad, A. S. (2013). Discovery of Human Zinc Deficiency: Its Impact on Human Health and Disease. Advances in Nutrition, 4 (2), 176-190. doi: https://doi.org/10.3945/an.112.003210

[7] Marushko, Y. V., Asonov, A. O. (2015). Clinical significance of zinc deficiency in children with chronic gastroduodenitis associated with Helicobacter pylori. Children's doctor, 3-4, 5-8.

[8] Marushko, Yu. V., Asonov, A. O., Gichka, S. G. (2014). Features of clinical course of chronic gastroduodenitis, morphological changes and gastroprotection state in children with zinc deficiency. Child`s health, 4, 7-12.

[9] Skrovanek, S., DiGuilio, K., Bailey, R., Huntington, W., Urbas, R., Mayilvaganan, B., Mullin, J. M. (2014). Zinc and gastrointestinal disease. World Journal of Gastrointestinal Pathophysiology, 5 (4), 496-513. doi: https://doi.org/10.4291/wjgp.v5.i4.496

[10] Podobed, V. M. (2015). Zinc Carnosin: a new formula of gastroprotection and making up zinc deficiency. Medical news, $2,17-20$.

[11] Gaby, A. (2017). Nutritional medicine. Concord, NH: Fritz Perlberg Publishing.

[12] Marushko, Y. V., Asonov, A. O. (2013). Gastroprotection study in children with chronic gastroduodenitis and zinc deficiency. Journal of the Grodno State Medical University, 4, 87-90.

[13] Sannikova, N. E., Shagiakhmetova, L. V., Osheva, T. M. (2007). Essential trace elements status of children and adolescents suffering chronic gastroduodenitis. Pediatric Nutrition, 5 (5), 12-17.

[14] Bulatov, V. P., Rylova, N. V. (2010). The mineral status at children with digestive diseases. Practical medicine, 3, 26-30.

[15] Ozturk, N., Kurt, N., Ozgeris, F. B., Kilic Baygutalp, N., Tosun, M. S., Bakan, N., Bakan, E. (2015). Serum Zinc, Copper, Magnesium and Selenium Levels in Children with Helicobacter Pylori Infection. The Eurasian Journal of Medicine, 47 (2), 126-129. doi: https://doi.org/10.5152/eurasianjmed.2015.104

[16] Valenzano, M. C., Mercado, J. M., Wang, X., Zurbach, E. P., Raines, J., McDonnell, E. et. al. (2014). Drug delivery of zinc to Barrett's metaplasia by oral administration to Barrett's esophagus patients. Therapeutic Delivery, 5 (3), 257-264. doi: https:// doi.org/10.4155/tde.13.151

[17] Shafaghi, A., Hasanzadeh, J., Mansour-Ghanaei, F., Joukar, F., Yaseri, M. (2016). The Effect of Zinc Supplementationon the Symptoms of Gastroesophageal Reflux Disease; a Randomized Clinical Trial. Middle East Journal of Digestive Diseases, 8 (4), 289-296. doi: https://doi.org/10.15171/mejdd.2016.38

[18] Johnsen, Ø., Eliasson, R. (1987). Evaluation of a commercially available kit for the colorimetric determination of zinc in human seminal plasma. International Journal of Andrology, 10 (2), 435-440. doi: https://doi.org/10.1111/j.1365-2605.1987.tb00216.x

[19] Nakaz Ministerstva okhorony zdorovia Ukrainy N 59 (29.01.2013). Unifikovanyi klinichnyi protokol medychnoi dopomohy ditiam iz hastroezofahealnoiu refliuksnoiu khvoroboiu. Sovremennaya pediatriya, 4, 20-31.

[20] Gammoh, N. Z., Rink, L. (2017). Zinc in infection and inflammation. Nutrients, 9 (6), 624. doi: https://doi.org/10.3390/ nu9060624 